\title{
PATTERNS OF TOTAL AND IONIZED CALCIUM AND OTHER ELECTROLYTES IN PLASMA DURING AND AFTER GENERAL SURGERY
}

\author{
R. Rodriguez, ${ }^{*}$ R.R. Jones, M.A. Adson and E.A. Moffitt $\dagger$
}

Calcrum plays a dominant role in many biochemical processes that are critical to body homeostasis. ${ }^{1}$ Blood clotting and muscle contraction are two mechanisms in which ionic calcium is essential. In the myofibril, calcium ions entering the cell on depolarization, and those freed from an intracellular bound form act to cause sarcomere shortening. ${ }^{2}$ The other electrolytes, sodium, potassium, magnesium, and inorganic phosphate are also necessary in proper concentrations for balanced biological systems. ${ }^{1}$

How much of what kinds of intravenous solution to give during operation is an everyday consideration for anaesthetists. Does giving dextrose in water alter the pattern of plasma electrolytes, particularly calcium, compared to giving Ringer's lactate solution? Seeking an answer, we studied 13 patients during anaesthesia for abdominal operations who received one or other of these two intravenous solutions.

\section{Patients Studied}

The six females and seven males averaged 55 years of age (range 39-76), and $77 \mathrm{~kg}$ weight (range 50-92). All were intra-abdominal operations, except for one herniorraphy. Their A.S.A. physical status categories were Class I-8 and Class II-5.

All patients were induced with thiopentone, given succinylcholine for intubation and maintained with nitrous oxide and tubocurare. In addition, halothane was given to all but two patients, who had Innovar ${ }^{(}$.

Nine patients, with a mean anaesthetic time of 123 minutes, received a mean volume of dextrose/water of $816 \mathrm{ml}$ during operation and for one hour in the recovery room. The group who received a mean volume of $707 \mathrm{ml}$ of 5 per cent dextrose/Ringer's lactate, averaged 116 minutes of anaesthesia. The intended flow rate was $250 \mathrm{ml}$ per hour over the three hours. No blood was transfused.

\section{Study Protocol}

Serial samples of venous blood were drawn in heparinized syringes, without tourniquet, before induction, at mid-operation and end-operation and one hour afterwards. Samples were iced and biochemical determinations began within 15 minutes. Blood-gas analyses were done by electrodes (Instrumentation Laboratory, Inc.) without correction for body temperature. Concentrations of several con-

"From the Departments of Anesthesiology and Surgery, Mayo Clinic and Foundation, Rochester, Minn., U.S.A. This work was supported in part by grant GM 14919 from the National Institutes of Health, Public Health Service.

†Present address: Department of Anaesthesia, Dalhousie University, Halifax, Nova Scotia. 


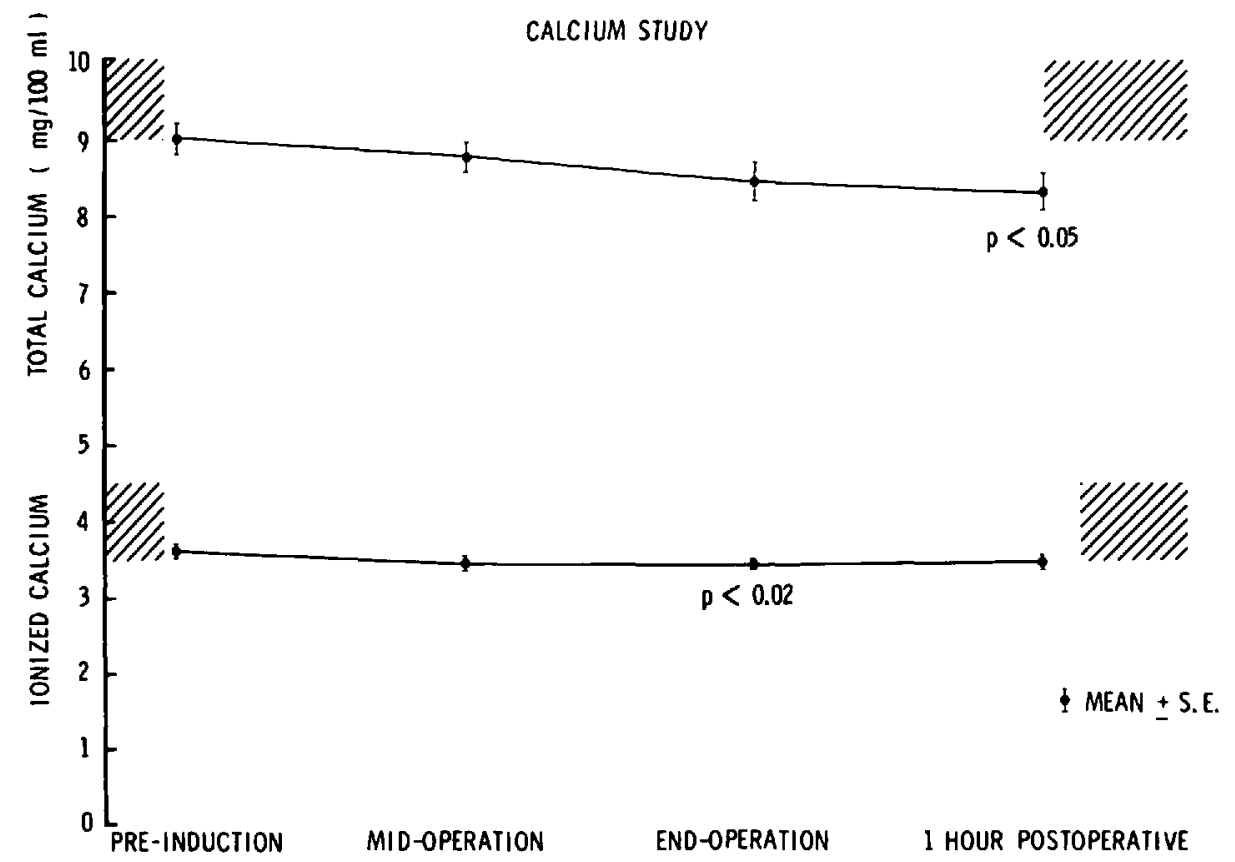

FIgure 1. Mean concentrations, \pm standard errors, in plasma of total and ionized calcium. Shaded areas are the normal range. Ionized calcium was decreased at end of operation and the total level, one hour later.

stituents of plasma were measured. Sodium and potassium concentrations were determined by flame photometry. Magnesium and total calcium values were obtained by an atomic absorption spectrophotometer (Perkin-Elmer Corp.). Inorganic phosphate was determined in an auto-analyzer (Technician Corp.). The plasma concentration of ionized calcium was determined by an electrode method. ${ }^{3}$ Total protein levels were done by refractometry and haematocrits in i micro centrifuge. Parathyroid hormone (PTH) was measured by radioimmunoassay, ${ }^{4}$ in which the antiserum binds to all known circulating species of the hormone. Statistical analysis of paired data was done, comparing concentrations of each variable in the three subsequent samples to that in the first sample before anaesthesia. Analysis of unpaired data was also done, comparing variables at the same sample time, from the two groups receiving different intravenous solutions. Differences at the 5 per cent level were considered significant.

\section{RESULTS}

Mean concentrations in plasma for nine variables plus haematocrit for the nine patients who received 5 per cent dextrose/water intravenously, are shown in Figures 1 to 5 .

Both total and ionized calcium levels were low normal before anaesthesia. There was a significant decrease in ionized calcium by the end of operation, while the total calcium was decreased after one hour in the recovery room (Figure 1). 
CALCIUM STUDY

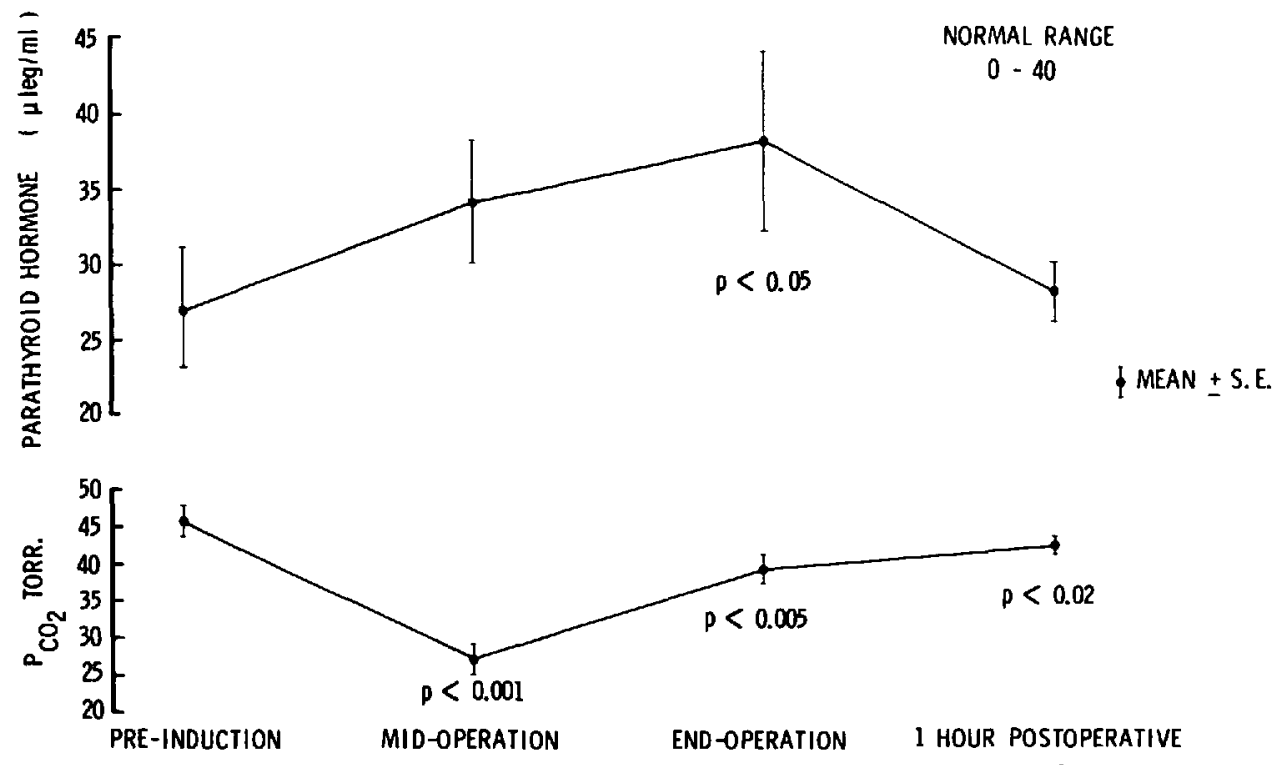

Frgure 2. Mean levels of $\mathrm{PTH}$ and $\mathrm{P}_{\mathrm{CO}}$ in nine patients during operation and one hour later. PTH was elevated at the end of anaesthesia, after two hours of reduced carbon dioxide tension.

Parathyroid hormone increased from 27 before anaesthesia to 38 microliter equivalents per $\mathrm{ml}$ at the end of operation. Carbon dioxide tension remained below the control level throughout the study (Figure 2).

Inorganic phosphate remained below control level through the study while magnesium decreased significantly only one hour post-operatively (Figure 3 ).

The amount of total proteins in plasma decreased from control value throughout the study, but remained in normal range. The mean haematocrit fell significantly at mid-operation (Figure 4).

Both potassium and sodium levels decreased from control for the whole studyperiod, and remained below normal range (Figure 5).

There were no differences in plasma levels of the variables between the groups receiving 5 per cent dextrose/water and 5 per cent dextrose/Ringer's solution, with one exception. Sodium levels were lower in the dextrose/water group at the end of operation and one hour later.

\section{Comment}

The advent of a reliable, practical method of measuring the ionized portion of calcium in plasma ${ }^{3}$ has been followed by a spate of studies on calcium behaviour. Kaplan et al. ${ }^{5}$ reported that metabolic alkalosis decreased total and ionized calcium levels in serum with a large increase in PTH. Small decreases in ionized calcium initiated an increase in PTH. Hinkle and Cooperman ${ }^{6}$ found a direct relationship of $\mathrm{Pa}_{\mathrm{CO}_{2}}$ and ionized calcium in plasma: a respiratory alkalosis accompanied by a decrease in ionized calcium. In addition they documented a temporary decrease in 

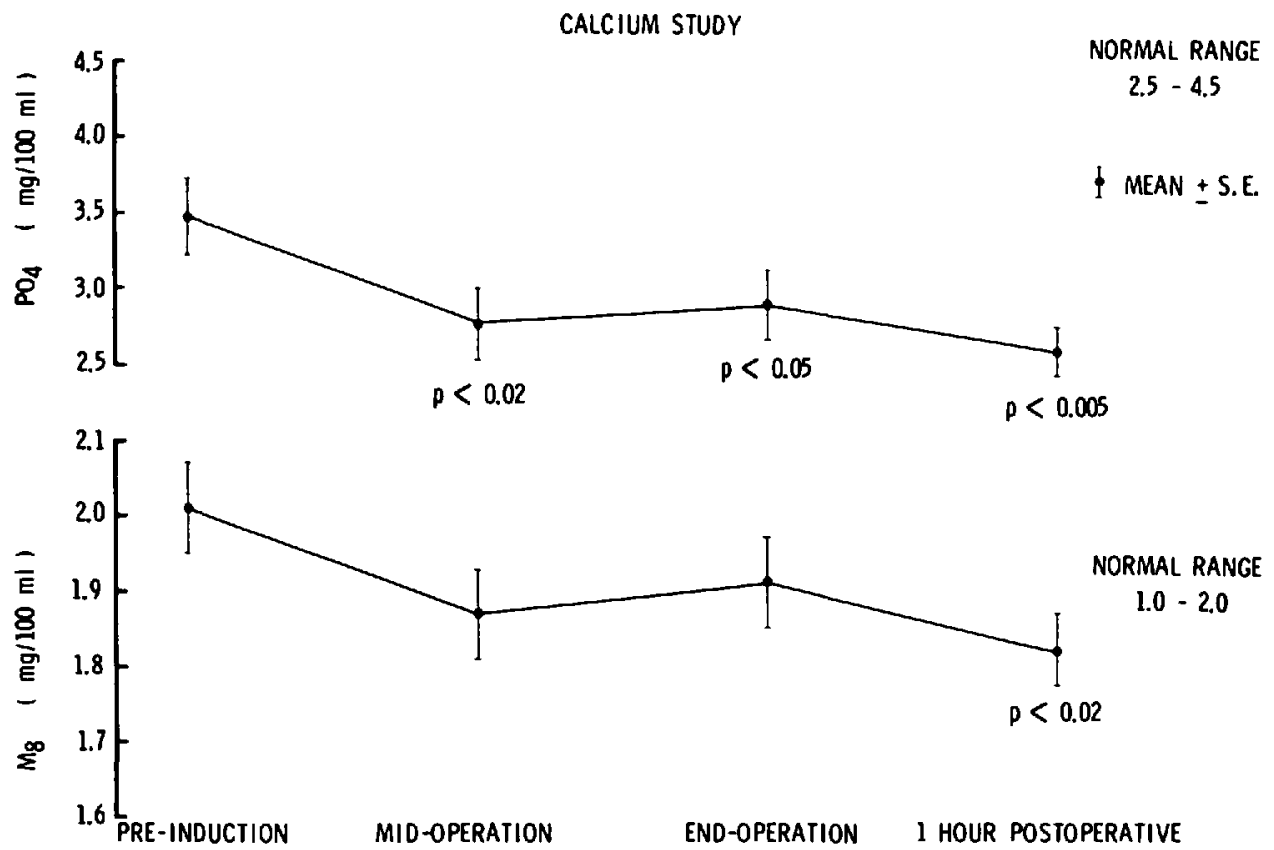

FIgure 3. Magnesium and phosphate concentrations in plasma, mean \pm S.E. $\mathrm{PO}_{4}$ was reduced throughout the study and $\mathrm{Mg}$ only one hour post-operatively.

CALCIUM STUDY
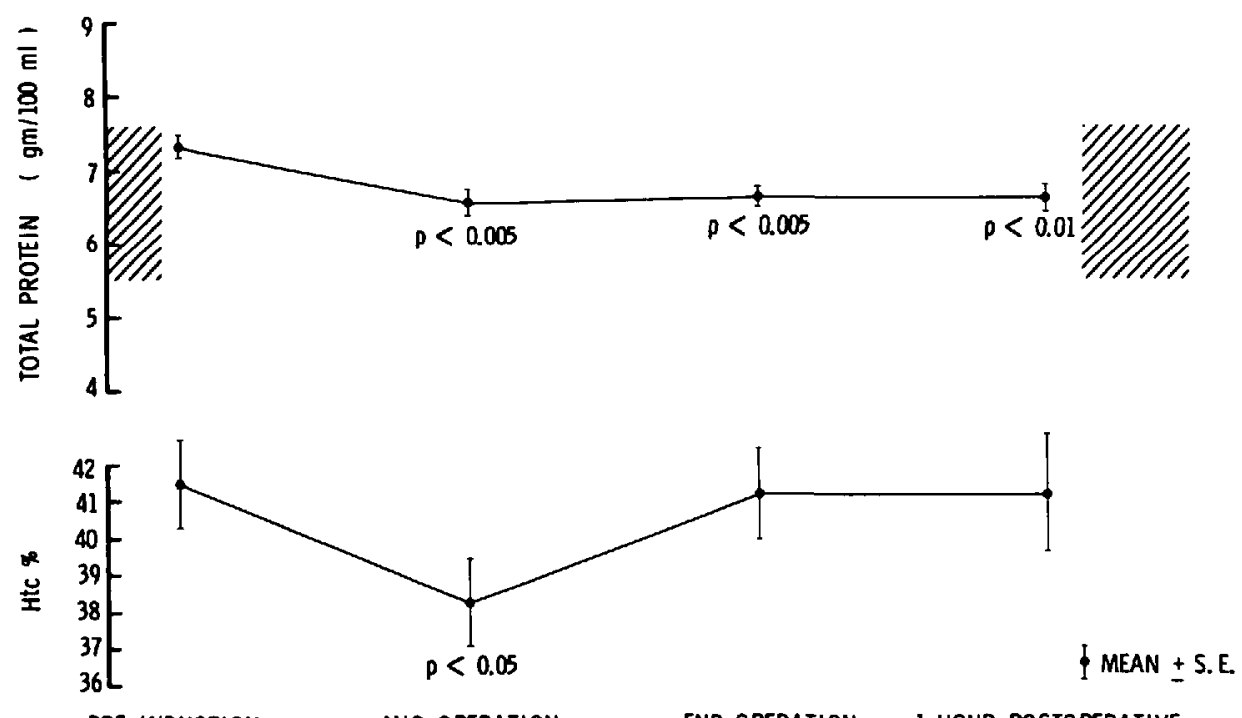

PRE-INDUCTION MID-OPERATION END-OPERATION I HOUR POSTOPERATIVE

Figure 4. Mean value for total protein concentration and haematocrit. Shaded areas indicate normal range. Proteins were reduced throughout which Het fell at mid-operation. 

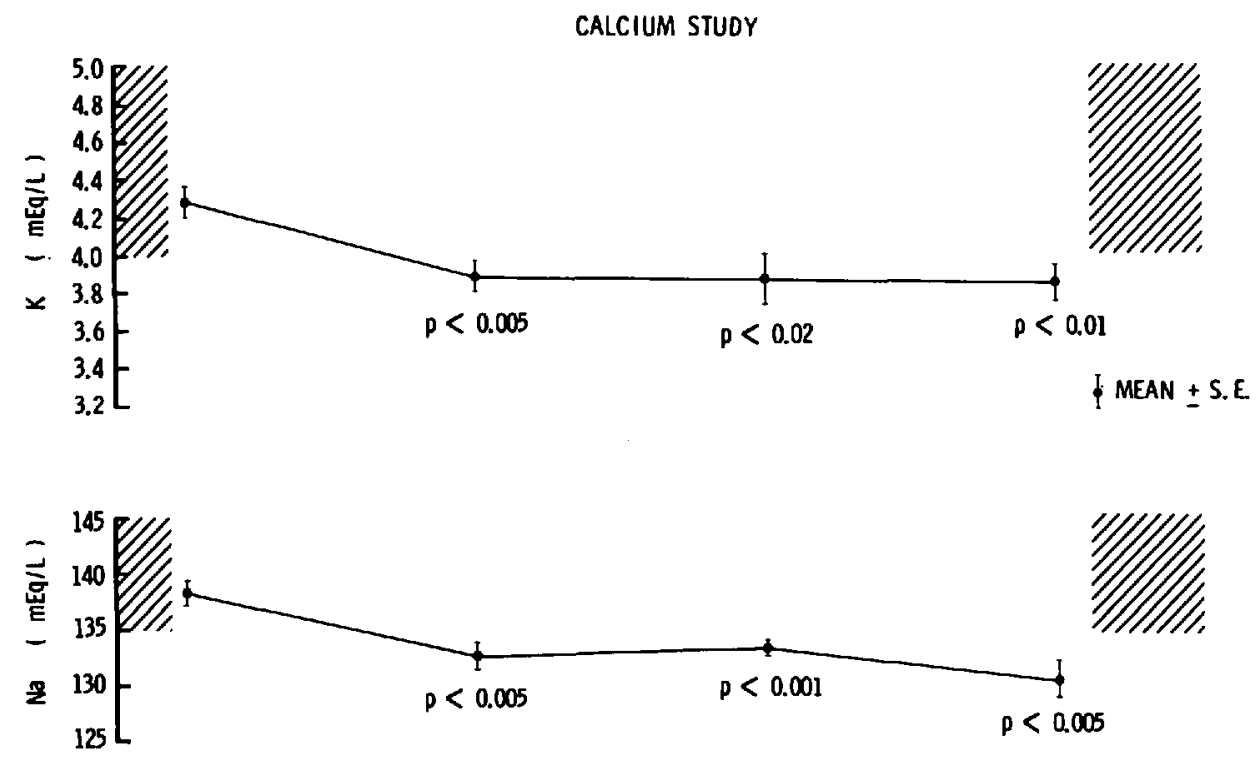

PRE-INDUCTION MID-OPERATION END-OPERATION I HOUR POSTOPERATIVE

Ficure 5. Mean values \pm S.E. for plasma potassium and sodium. Shaded areas indicate normal range. Both electrolytes decreased for the duration of the sudy.

ionized calcium during rapid transfusion of blood, due to binding of ionic calcium by citrate.

Several groups have followed the calcium changes through cardiopulmonary bypass, an event marked by multiple disruptive influences, such as haemodilution, large amounts of ACD blood and exogenous calcium. ${ }^{7-9}$ Ionized calcium decreased from citrate in the pump prime, and all authors advocate supplemental $\mathrm{CaCl}_{2}$ to maintain plasma total and ionic levels during and after cardiac operation.

The present study was done as background information to our previous one on calcium behaviour in cardiac surgery. ${ }^{10} \mathrm{We}$ had found what happens with the ever-changing factors of whole body perfusion, but what happens during anaesthesia and general surgery, when the only additions are the usual intravenous solutions?

The answer in brief is - no great changes. We also found the decrease in ionized calcium in plasma of patients one hour after anaesthesia, after three hours of respiratory alkalosis. The increase of PTH was seen at the end of operation, and reverted to control level within an hour. There is an emerging body of information that respiratory alkalosis during anaesthesia is disadvantageous and maybe even has detrimental effects. Nisbet and co-workers ${ }^{11}$ have found that $\mathrm{Pa}_{\mathrm{CO}_{2}}$ decreased and $\mathrm{A}-\mathrm{aD}_{\mathrm{O}_{2}}$ rose significantly in dogs ventilated at low $\mathrm{Pa}_{\mathrm{CO}_{2}}$. This is an adverse respiratory effect. Our present study indicates that with respiratory alkalosis, both plasma ionized calcium and potassium concentrations decrease. These could result in adverse circulatory effects since calcium ion is critical to effective interaction of actin and myosin, to produce myocardial contraction. Similarly, a reduced potassium ion level in plasma and in the myocardium is involved in hyperirritable ectopic rhythms. Perhaps these changes are not of significance in patients with normal 
hearts but could worsen the situation in the presence of impaired cardiac function and hypokalaemia.

The general effect of two hours of anaesthesia and operation and three hours of administration of intravenous solution at about $250 \mathrm{ml}$ per hour was mild haemodilution. This may also have been partially due to migration of water to the vascular compartment from the interstitial space.

All electrolytes tended to decrease by small but statistically significant amounts. Sodium, potassium, phosphate, and magnesium decreased regardless of whether water or balanced electrolyte solution was given. Only plasma $\mathrm{Na}^{+}$remained higher with Ringer's lactate than with dextrose/water. This gradual, small decrease in plasma electrolytes during abdominal surgery was noted in another group of patients receiving clear intravenous solutions. ${ }^{12}$ With the relatively slow rate of infusion and at least some unreplaced blood loss, it is surprising to find haemodilution.

The small but seemingly real fall in haematocrit at mid-operation supports haemodilution, as does the consistent decrease in total proteins. Since 39.5 per cent of total plasma calcium is protein-bound, a protein decrease goes along with a total calcium decrease. The remainder of plasma calcium is 46.9 per cent ionized and 13.6 per cent diffusible, but not ionized. ${ }^{3}$

\section{SUMMARY}

Thirteen patients were studied during two hours of anaesthesia for abdominal operations and for an hour post-operatively. Serial venous blood samples were taken for determination of plasma total and ionized calcium, acid-base variables, $\mathrm{Na}, \mathrm{K}, \mathrm{Mg}, \mathrm{PO}_{4}$ total proteins and parathyroid hormone. One group of patients received 5 per cent dextrose/water and the other 5 per cent dextrose in Ringer's solution, at $250 \mathrm{ml}$ per hour. Total and ionized calcium levels decreased toward the end of operation and an hour later, associated with respiratory alkalosis. Parathyroid hormone increased at the end of operation, as an effect of the decreased ionized calcium. The general effect was mild haemodilution with all the other electrolytes decreasing, as did total protein concentration.

\section{RÉsuMé}

Des prélèvements veineux ont été faits chez 13 opérés durant des anesthésies d'une durée de 2 heures et ont été répétés durant la première heure postopératoire. Les paramètres étudiés ont été le calcium total et le calcium ionisé, l'équilibre acido-basique, le sodium, le potassium, le magnésium et les phosphates, les protéines totales et la parathormone. Un groupe de patients a reçu du dextrose à 5 pour cent dans l'eau et l'autre groupe a reçu une solution de dextrose à 3 pour cent dans le Ringer, à raison de $250 \mathrm{ml}$ à l'heure.

Les taux de calcium total et ionisés étaient diminués vers la fin de l'intervention et dans l'heure suivant l'intervention, ceci associé avec une alcalose respiratoire. Les taux de parathormone s'élevaient en fin d'intervention, un effet lié 
à la diminution du calcium ionisé. Quant aux autres électrolytes et aux protéines totales, leurs taux reflétaient une hémodilution légère.

\section{ACKNOWLEDGMENTS}

The authors thank the staff of Dr. R.S. Goldsmith's laboratory who performed the measurements of ionized calcium and PTH, and Mrs. Rita Nelson for her fine work in the Anaesthesiology Laboratory.

\section{REFERENCES}

1. Williams, R.J.P. \& WaCker, W.E.C. Cation balance in biological systems. J.A.M.A. 201 : 96 (1967).

2 Entman, M.L. Calcium and cardiac contractility. Amer. J. Med. Sciences 259: 164 (1970).

3. Moone, E.W. Ionized calcium in normal serum, ultrafiltrates, and whole blood determined by ion-exchange electrodes. J. Clin. Invest. 49: 318 (1970).

4. Arnaud, C.D., TsaO, H.S., \& LitTLEDIKE, T. Radioimmunoassay of human parathyroid hormone in serum. J. Clin. Invest. 50: 21 (1971).

5. Kaplan, E.L., Hill, B.J., Locke, S., \& Peskin, G.W. Acid-base balance and parathyroid function: metabolic alkalosis and hyperparathyroidism. Surgery 70: 198 (1971).

6. HinkLE, J.E. \& Cooperman, L.H. Serum ionized calcium changes following citrated blood transfusion in anaesthetized man. Br. J. Anaes. 43: 1108 (1971).

7. Das, J.B., Eraklis, A.J., Adams, J.G., Jr., \& Gross, R.E. Changes in serum ionic calcium during cardiopulmonary bypass with hemodilution. J. Thorac. Cardiovasc. Surg. 62: 449 (1971).

8. Killen, D.A., Ghogan, E.L., II, Gower, R.E., Collins, I.S., \& Collins, H.A. Effect of ACD blood prime on plasma calcium and magnesium. Ann. Thorac. Surg. 13: 371 (1972).

9. Johnson, A.E., RADDE, I.C., NISBET, H.I.A., \& TAYLOR, U. Effects of altering calcium in haemodiluted pump primes on sodium and potassium in children undergoing open-heart operations. Can. Anaesth. Soc. J. 19: 517 (1972).

10. Mofritr, E.A., Tarhan, S., Goldsmith, R.S., Pluth, J.R., \& McGoon, D.C. Patterns of total and ionized calcium and other electrolytes in plasma during and after cardiac surgery. J. Thorac. Cardiovasc. Surg. 65: 751 (1973).

11. Nisbet, H.I.A., Mathur, A.K., Dobbinson, T.L., Steward, D.J., \& Volgyesi, G.A. The effect of artificial ventilation on FRC and arterial oxygenation. 3. Low and normal arterial carbon dioxide tension during ventilation with sine wave and inspiratory hold patterns. Canad. Anaesth. Soc. J. In Press.

12. Moffitt, E.A., SchnelLe, N., Rodriguez, R., Lee, R.A., \& Judd, E.S. Effects of intravenously administered solutions on electrolytes and energy substrates during surgery. Canad. Anaesth. Soc. J. 21: 285 (1974). 